\title{
An epistle to Dr Robicsek
}

\author{
W. Randolph Chitwood, Jr, MD
}

See related editorial: Robicsek F. Robotic cardiac surgery: Quo vadis? J Thorac Cardiovasc Surg. 2003;126:623-4.
Surgery of the heart has probably reached the limits set by nature to all surgery. -Stephen Paget, 1897

If I have been able to see further, it was only because I stood on the shoulders of giants. -Isaac Newton

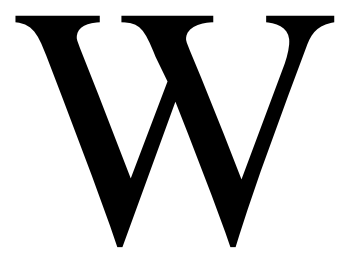

ell, Dr Robicsek, we meet again! It is interesting to me that you-one who has been such an innovator and so progressive in cardiac surgery-now are so skeptical of robotic cardiac surgery. I have always revered your analysis and advice. Therefore, it seems prudent to consider your thoughts. I am sure that, as a well intentioned expert, you are trying to save from us the embarrassment of failure, acceptance of an inferior clinical result, the added cost to health care, the possibility of patient injury, or the stresses associated with untying the Gordian knot of closed chest cardiac surgery.

Your vision for future cardiac surgery may be somewhat pixelated, but it does beg our consideration. Surgeons have always sought to provide the best care for their patients, and this will not cease with the development of new technology. Moreover, operations evolve, become standard, and then fade away. You probably were an excellent tuberculosis surgeon. Moreover, I was trained to ablate a Kent pathway surgically. However, new tuberculosis drugs and catheter technologies made both of us obsolete regarding these operations. I expect that there will be a major role for robotics in cardiac surgery, at least for a while.

I believe that better robotic devices are needed and that training must be different. However, the elegance of performing a mitral valve repair in a closed chest or even in a beating heart has a certain excitement and appeal for both patient and surgeon. To be sure, we are far from the routine use of robotics to perform coronary and valve surgery, but we are on the precipice of success. The accuracy of the robotic micro-wrists and 3-dimensional vision surpasses 2-dimensional endoscopic operations using long instruments, especially for reconstructive operations. As one who has done many operations using both methods, tele-manipulation of tissues is a great advancement. For sure, enabling technologies will help us to improve operative speed. However, to determine the true benefits, surgeons must keep and analyze detailed operative and follow-up data. To establish the efficacy of robotic cardiac surgery and operative quality, surgeons must evaluate each operation in large patient series. We cannot capitulate regarding operative quality.

So, as one having had a sternotomy, I can tell you, Dr Robicsek, that there is a certain appeal to a small incision. Moreover, when you now see your grandchildren bounding to their Pentium chip-driven computers to perform finite element and Fourier analysis on their golf swings, you can be sure that someone will improve on our current robotic mousetrap. To heed your caution is wise, but to stop developing what many of us consider promising potential in the line of surgical succession is unwise. Current robotic coronary surgery data suggest that you could be rightusing the anastomotic techniques of today. What new enabeling device will appear 
tomorrow? Our early successes in repairing the mitral valve suggest that your grandchildren will do it better than we have done it.

I have never considered you a Stephen Paget in your view of the future of cardiac surgery. More likely, you epitomize Isaac Newton's allusion to the fact we have stood on your shoulders to see so far ahead. Sir, give robotic and computer-assisted surgery a chance to develop and time will prove either the value or folly. The conscience of the surgical and patient community will direct the course.

\section{Editor's note: A response from Dr Francis Robicsek}

Time will tell.

Francis Robicsek, $M D$

Charlotte, NC

The Journal of Thoracic and Cardiovascular Surgery Conflict of Interest Policy

To assure fairness to authors submitting work for consideration in The Journal of Thoracic and Cardiovascular Surgery, a mechanism exists for managing conflicts of interest. The editor and each of the section editors complete a "Conflict of Interest" form that identifies any and all relationships with commercial and other academic entities. When the editor has a potential conflict because of a relationship with another entity or author, the editor appoints an alternate editor from among the section editors or editorial board members who assumes the entire responsibility for final decisions on the manuscript in question. The editor does not read the reviews that are submitted nor engage in discussing the manuscript prior to the final decision. When the conflict of interest involves a section editor, a "guest section editor" is appointed who fills the role normally played by the conflicted section editor. All members of the editorial board and reviewers are asked to indicate any conflict of interest when they agree to review a manuscript. 